Eduard I. Dedkov - Tatiana Y. Kostrominova

Andrei B. Borisov $\cdot$ Bruce M. Carlson

\title{
Survival of Schwann cells in chronically denervated skeletal muscles
}

Received: 21 September 2001 / Revised, accepted: 12 November 2001 / Published online: 5 February 2002

(C) Springer-Verlag 2002

\begin{abstract}
It is well established that over time Schwann cells disappear from the endoneurial space of the distal stump of a chronically transected sciatic nerve trunk. Nevertheless, the status of the Schwann cells within terminal branches of the transected sciatic nerve remains poorly understood. To elucidate this issue we examined the endoneurial space of the intramuscular nerves in rat hindlimb skeletal muscles, which had been denervated for a 25-month period. Based on specific ultrastructural characteristics, we identified a small population of viable Schwann cells within the intramuscular nerve trunks. The surviving Schwann cells continued to be immunopositive for both S-100 protein and neural cell adhesion molecule. In addition, reverse transcription-polymerase chain reaction and/or Western blot analyses have shown that at least two molecules, brain-derived neurotrophic factor and a non-catalytic truncated form of tyrosine protein kinase receptor B, which could potentially participate in the process of nerve repair, were detectable in chronically denervated skeletal muscle. Our results demonstrate that Schwann cells can survive inside the intramuscular nerve trunks of denervated skeletal muscle for a 25 -month period without axonal contact.
\end{abstract}

Keywords Axotomy - Muscle denervation - Schwann cells $\cdot$ Neural cell adhesion molecule $\cdot \mathrm{S}-100$ protein

E.I. Dedkov and T.Y. Kostrominova contributed equally to this work.

E.I. Dedkov (汭 · T.Y. Kostrominova · A.B. Borisov

B.M. Carlson

Department of Cell and Developmental Biology,

4643 Medical Sciences II Building, University of Michigan,

Ann Arbor, MI 48109, USA

e-mail: ededkov@umich.edu,

Tel.: +1-734-7632552, Fax: +1-734-7631166

T.Y. Kostrominova $\cdot$ B.M. Carlson

Institute of Gerontology, University of Michigan,

Ann Arbor, MI 48109, USA

\section{Introduction}

Extended delay in the repair of the transected sciatic nerve or its branches progressively reduces the capacity of the regenerating axons to grow through the distal stump [7, 14, 20, 29, 37, 44]. Morphological analysis of chronically transected peripheral nerves has shown that significant fibrosis and remodeling within the endoneurial space of a distal stump are always associated with atrophy and degeneration of the Schwann cells [2, 31, 45].

The Schwann cells remaining in the nerve stumps play a crucial role in the elongation and guidance of regenerating axons $[10,27,42]$. There is clear evidence that the Schwann cells distal to the site of a nerve lesion begin to synthesize proteins associated with axonal regeneration $[6,15,22,40]$. Nevertheless, the ability of Schwann cells to express the majority of regeneration-associated molecules is eventually down-regulated with increasing duration after lesion of the sciatic nerve [20, 21, 47].

Extensive and prolonged mRNA and/or protein expression of several regeneration-associated molecules, such as brain-derived neurotrophic factor (BDNF) $[8,9$, 25], neural cell adhesion molecule (N-CAM) [4, 24], and low-affinity neurotrophin receptor (p75) [12, 38, 39, 47], have been reported in the Schwann cells of the distal stump of a chronically transected sciatic nerve.

Despite the fact that information about the fate of Schwann cells remaining in the extra-organ segment of the distal stump of chronically non-regenerated sciatic nerve is now available, there are no data concerning the status of the Schwann cells in the intra-organ nerve terminals. To elucidate this issue we have examined the small intramuscular nerve branches of 25-month denervated skeletal muscles of the rat hindlimb. Viable Schwann cells were demonstrated within the endoneurial space of the intramuscular nerve trunks at the ultrastructural level and by immunohistochemical staining for both S-100 protein (S100) and N-CAM. BDNF and trkB T mRNA transcripts and/or proteins were detected in 25-month denervated muscle. 


\section{Materials and methods}

Animals and surgical procedures

Unilateral denervation of the hindlimb skeletal muscles was conducted on four 4-month-old rats of the WI/HicksCar strain. The right sciatic nerve was exposed high in the thigh and sutured with silk in two places. A $0.5-\mathrm{cm}$ section of the nerve was removed between the sutures. Both proximal and distal nerve stumps were implanted into the nearby muscles as far away from each other as possible [43]. The operations and subsequent animal care were carried out in accordance with the guidelines of the Unit for Laboratory Animal Medicine at the University of Michigan. After the operations, the rats were treated with oral terramycin for 5 days. At 29 months of age the extensor digitorum longus (EDL), tibialis anterior (TA), soleus and gastrocnemius muscles were removed from denervated and contralateral legs of each rat, and the animals were killed by an overdose of anesthetic. The muscles from the intact contralateral legs of four 29-month-old rats served as controls. In addition, brain, gastrocnemius muscle, normal sciatic nerve (SN) and a distal stump of 2-month transected sciatic nerve (dSN) from three 28-month-old rats served as supplementary controls in reverse transcription (RT)-PCR and/or Western blot analyses.

\section{Light and transmission electron microscopy}

Small pieces from four denervated and contralateral control EDL and soleus muscles were fixed with a mixture of $4 \%$ paraformaldehyde and $2.5 \%$ glutaraldehyde in $0.1 \mathrm{M}$ phosphate-buffered saline pH7.4 (PBS), washed in PBS and post-fixed in $1 \% \mathrm{OsO}_{4}$. Samples were dehydrated in an ascending series of ethanol, passed through absolute acetone and embedded in resin using an Eponate 12Araldite 502 Kit (Ted Pella, Redding, Calif.). Transverse 1.0- $\mu \mathrm{m}$ sections were cut with an ultramicrotome and mounted on slides; they were stained with toluidine blue and examined under the light microscope. Ultrathin sections including the cross-sectioned profiles of nerve trunks were collected on formvar-coated slot grids, contrasted with uranyl acetate and lead citrate, and examined with a Philips CM-100 transmission electron microscope.

\section{Immunohistochemistry}

Cross-sections, $0.5 \mathrm{~cm}$ thick, from both denervated and contralateral control EDL and TA muscles were fixed in freshly prepared $2 \%$ paraformaldehyde in PBS for $12 \mathrm{~h}$ at $+4^{\circ} \mathrm{C}$, washed overnight in PBS, cryo-protected in a graded sucrose series and placed in specimen molds containing TBS/Tissue Freezing Medium (Triangle Biomedical Sciences, Durham, N.C.). The muscles were quickly frozen in isopentane that had been pre-cooled by dry ice. Transverse 9.0- $\mu \mathrm{m}$ sections were cut with a cryostat and mounted on glass slides. The serial sections were double labeled with mixtures of different primary antibodies for $3 \mathrm{~h}$ at $+37^{\circ} \mathrm{C}$. The primary antibodies used were: (1) rabbit anti-chicken NCAM $(2 \mu \mathrm{g} / \mathrm{ml}$, Chemicon International, Temecula, Calif.), (2) rabbit anti-cow S100 (1:200, DAKO, Carpinteria, Calif.) and (3) mouse anti-rat laminin B2, clone D18 [undiluted supernatant, Developmental Studies Hybridoma Bank (DSHB), The University of Iowa, Iowa City, Iowa]. After staining, the sections were washed in PBS and labeled with a mixture of FITC- and Cy3-conjugated goat antimouse and goat anti-rabbit secondary antibodies (Jackson ImmunoResearch Laboratories), respectively, for $45 \mathrm{~min}$ at room temperature. The sections were rinsed in PBS, mounted in Vectashield mounting medium for fluorescence with DAPI to label the nuclei (Vector Laboratories, Burlingame, Calif.), and were coverslipped. Observation and photography of the sections were made with a Zeiss Axiophot-2 Universal Microscope (Carl Zeiss, Germany).

\section{RT-PCR}

Total RNA was isolated from cross-cut halves of four denervated and control gastrocnemius muscles, as well as from three brains, sciatic nerves, and the distal stumps of 2-month transected sciatic nerves, by homogenization in TRIzol (Gibco-BRL, Grand Island, N.Y.), followed by a single step purification method as described by the manufacturer's protocol. Total RNA concentration was estimated using a spectrophotometer, and an equal amount of total RNA ( $2 \mu \mathrm{g} /$ reaction) was reverse-transcribed to synthesize singlestranded cDNA by using the ThermoScript RT-PCR System (Gibco-BRL) according to the manufacturer's protocol. PCR amplification was performed using the following conditions: $2 \mu \mathrm{l}$ of single-stranded cDNA from an RT reaction was amplified at $95^{\circ} \mathrm{C}$ for $1 \mathrm{~min}, 52^{\circ} \mathrm{C}$ for $1 \mathrm{~min}$, and $72^{\circ} \mathrm{C}$ for $1 \mathrm{~min}$ for 30 cycles. The PCR products were run on a $1 \%$ agarose gel and visualized by ethidium bromide staining. The PCR reactions were in the linear range with respect to input of the RNA. Primers used for amplification were: (1) BDNF, 5'-GAG CTG AGC GTG TGT GAC AG-3' forward and 5'-GGT CAG TGT ACA TAC ACA GG-3' reverse, with a 318-bp PCR product [19]; (2) trkB T - non-catalytic truncated form of tyrosine protein kinase receptor $\mathrm{B}, 5^{\prime}$-CCA CTA GGA TTT GGT GTA CC-3' forward and 5'-CCA CTG TCA TCC GAT GAA AT-3' reverse, with a 664-bp PCR product [19]; (3) trkB FL - full-length of the trkB, 5'-TTC GGT ATC ACC AAC AGC CAG-3' forward and 5'-CTC GGT GGG CGG GTT ACC CTC-3' reverse, with a 387-bp PCR product [19]; and (4) p75, 5'-GAG CCG TGC AAG CCG TGC ACC-3' forward and 5'-CTC AGG CTC CTG GGT GCT GGG-3' reverse, with a 438-bp PCR product [48]. To control for equal amounts of input, primers specific to the glyceraldehyde 3-phosphate dehydrogenase were used: GAPDH, 5'-GGT GAA GGT CGG TCT CAA CGG A-3' forward and 5'-CCA CAG ATG CCA AAG TTG TCA TGG A-3' reverse, with a 505-bp PCR product. PCR amplification for GAPDH was performed using the following conditions: $0.5 \mu \mathrm{l}$ of single-

Fig. 1A-F Electron micrographs of cross-sectioned intramuscular nerve trunks from 25-month denervated soleus and EDL muscles illustrate the general envelope ultrastructure and cell phenotypes. A A single layer of wrinkled and flattened perineurial cells outlines the endoneurial space of the intramuscular nerve trunk from soleus muscle (arrowheads). B High magnification of the area shown in $\mathbf{A}$ by a straight asterisk. The perineurial cells are covered by basal laminae on both inner and outer surfaces (arrowheads). Note that the processes of the fibroblast-like cells show a parallel arrangement with respect to the perineurial cells (small arrows). A group of surviving Schwann cells covered by a common basal lamina (big arrows) is surrounded by collagen fibrils. C Two layers of perineurial cells (arrowheads) surrounding the endoneurial space of the nerve trunk from EDL muscle. Note an endoneurial blood vessel formed by endothelial cells (asterisks) and pericytes (small arrows). Big arrows point the surviving Schwann cells. D An endoneurial fibroblast-like cell does not possess a basal lamina. Its cytoplasm shows the presence of rough endoplasmic reticulum (arrows). Note the adjacent Schwann cell completely covered by a basal lamina (arrowheads). E High magnification of the area shown in $\mathbf{A}$ by a rounded asterisk. The Schwann cell body and cell processes are entirely covered by a basal lamina (arrowheads). The big arrow points to a bundle of collagen fibrils enclosed by Schwann cell processes: the inset shows the enlarged area of contact between two Schwann cell processes (arrows) that form a structure resembling pseudo-mesaxon (arrowhead) surrounding a bundle of collagen fibrils (asterisk). Note that the flattened processes of the two adjacent fibroblast-like cells, which contain abundant rough endoplasmic reticulum, overlap each other (small arrows). F Schwann cell located in a very small diameter nerve trunk profile from EDL muscle. Note the presence of both caveolae in the plasmalemma of the perineurial cells (arrowheads) and micropinocytotic vesicles in their cytoplasm (arrows) (EDL extensor digitorum longus). Bars A $5 \mu \mathrm{m}, \mathbf{B}-\mathbf{D} 2 \mu \mathrm{m}, \mathbf{E}, \mathbf{F} 1 \mu \mathrm{m}$ 

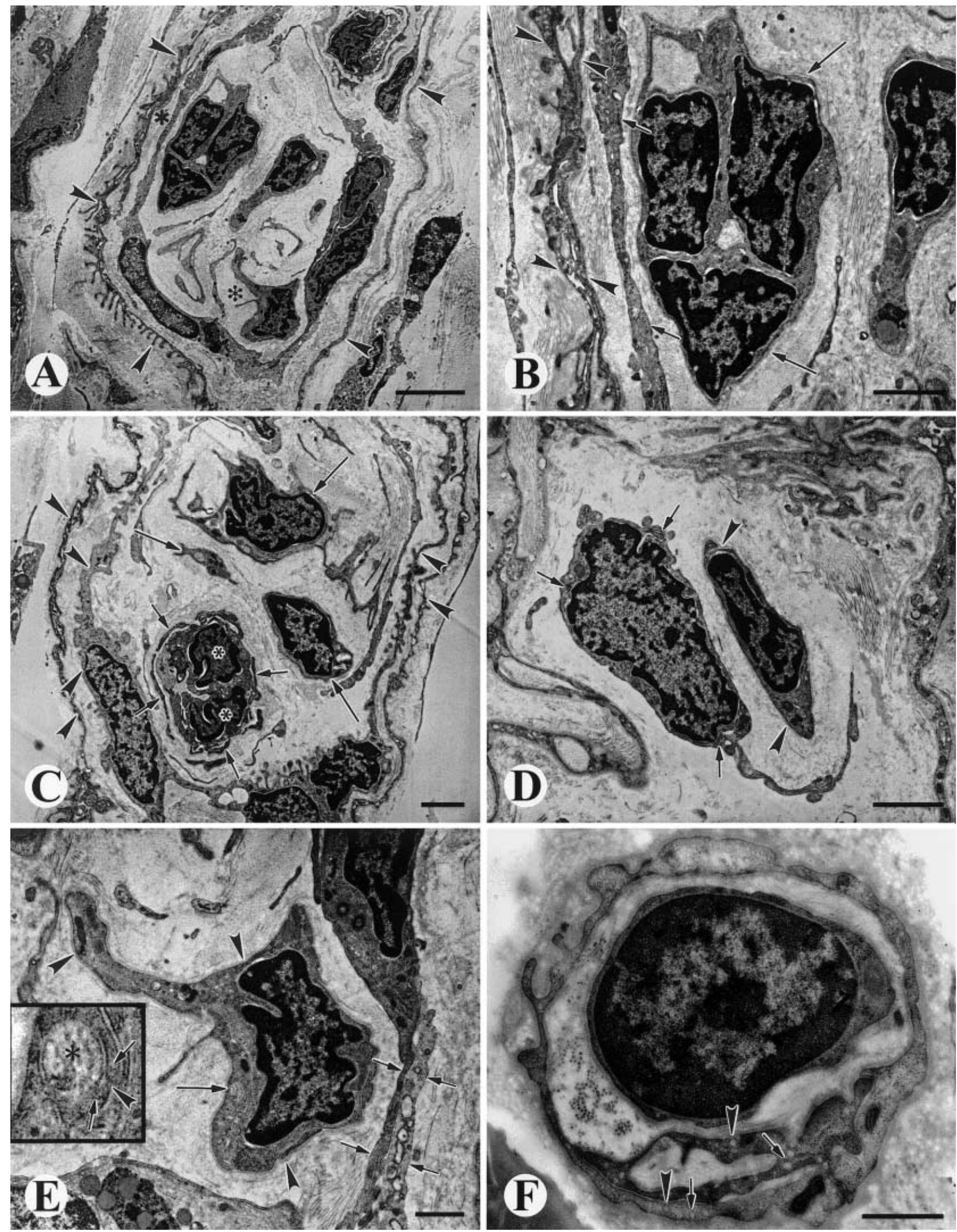
stranded cDNA from an RT reaction was amplified at $95^{\circ} \mathrm{C}$ for $1 \mathrm{~min}, 60^{\circ} \mathrm{C}$ for $1 \mathrm{~min}$, and $72^{\circ} \mathrm{C}$ for $1 \mathrm{~min}$ for 30 cycles.

\section{Western blot analysis}

Frozen cross-cut halves of four denervated and control gastrocnemius muscles, as well as three brains and sciatic nerves, were homogenized in a solution containing $20 \mathrm{mM}$ TRIS- $\mathrm{HCl}(\mathrm{pH} \mathrm{6.8)}$, $4 \%$ SDS (wt/vol), $1 \mathrm{mM}$ phenylmethylsulfonyl fluoride and $1 \mu \mathrm{M}$ each of leupeptin and pepstatin A. Protein concentrations were determined using Bio-Rad detergent compatible protein assay (Hercules, Calif.). Equal amounts of protein from each sample $(50 \mu \mathrm{g} /$ lane) were mixed with loading buffer, subjected to SDS-polyacrylamide gel electrophoresis under reducing condition and transferred electrophoretically to Immobilon-P membranes (Millipore, Bedford, Mass.). Gels with identical samples were stained with Coomassie brilliant blue and used as a supplementary control for equal amounts of protein loading. After transfer, the Immobilon-P membranes were blocked in Blotto buffer containing 5\% dry milk in PBS- $0.05 \%$ Tween-20 and then incubated overnight with primary antibodies at $+4^{\circ} \mathrm{C}$. The following antibodies were used: rabbit anti-BDNF $(1 \mu \mathrm{g} / \mathrm{ml}$, Chemicon International), mouse antitrkB, clone 47 (1:1,000, Transduction Laboratories, Lexington, Ky.), and mouse anti-nerve growth factor receptor $\mathrm{p} 75$, clone 192 ( $1 \mu \mathrm{g} / \mathrm{ml}$, Chemicon International). Immunodetection was done using peroxidase-conjugated goat anti-rabbit and goat anti-mouse secondary antibody (1:5,000, Jackson ImmunoResearch Lab., West Grove, Pa.) with subsequent chemiluminescence (ECL, Amersham Pharmacia Biotech, Piscataway, N.J). Each blot was scanned and images were stored in Adobe Photoshop format. In the final figures representative images were used.

\section{Results}

A small population of Schwann cells remains within chronically denervated skeletal muscles

Electron microscopy on transverse sections of 25-month denervated EDL and soleus muscles showed that despite the severe degree of muscle atrophy and significant interstitial fibrosis, the envelopes of intramuscular nerves were recognizable in the perimysium (Fig. 1A, C). The profiles of nerve trunks were well outlined by the perineurium, consisting of one or two layers of narrow and wrinkled perineurial cells, connected to each other by means of tight junctions in the areas of overlapping cell processes (Fig. 1B). Both inner and outer surfaces of the perineurial cell bodies as well as branching cytoplasmic processes that directly contact the perimysial and endoneurial connective tissue were covered by a continuous basal lamina. Occasionally, micropinocytotic vesicles were observed in the cytoplasm of elongated processes of the perineurial cells, whereas the plasmalemma showed the presence of caveolae (Fig. 1F). Although the majority of large intramuscular nerve trunks were mostly filled by collagen, at least four distinct cell types were still recognizable inside the endoneurial space of small nerve trunks. Endothelial cells, pericytes, fibroblast-like cells, and Schwann cells were identified on the basis of their distinctive morphological features. The endothelial cells and pericytes were also identified by their structural arrangement relative to the wall of the endoneurial blood vessels (Fig. 1C). The fibroblast-like cells did not possess a basal lamina (Fig.
1D, E) and demonstrated developed rough endoplasmic reticulum in the cytoplasm (Fig. 1E). Occasionally, these cells showed a parallel arrangement with respect to the perineurial cell layers and, at times, their adjacent thin processes overlaped in a manner similar to that of the perineurial cells (Fig. 1B, E). Endoneurial fibroblasts were the most difficult cell type to distinguish from atrophic Schwann cells. However, at the ultrastructural level, Schwann cells were differentiated from the fibroblast-like cells by having a continuous basal lamina that surrounded both cell body and closely packed small cell processes (Fig. 1B, D, E). Occasionally, the processes of Schwann cells curled around a bundle of the collagen fibrils, showing a pseudo-mesaxon formation (Fig. 1E, inset). Furthermore, Schwann cells were observed inside a very small nerve profile located in the endomysium (Fig. 1F).

Surviving Schwann cells continue to be immunopositive for S100 and N-CAM

Immunodetection of S100 and N-CAM within the endoneurial space of intramuscular nerves of 25-month denervated TA and EDL muscles was simultaneously carried out with labeling of the intact contralateral muscles. A pattern of nerve trunk structures was obtained by supplementary staining with laminin. In a contralateral control 29-month-old TA muscle, the majority of Schwann cells forming both myelinated and unmyelinated nerve fibers were intensely positive for S100 (Fig. 2A), whereas the laminin positive perineurial cells, outlining a nerve profile, were completely unstained for S100 (Fig. 2C). At the same time, only a few N-CAM-positive Schwann cells ensheathing the unmyelinated nerve fibers were seen in the endoneurial space of the same nerve profile (Fig. 2C, D).

Fig. 2A-J Immunofluorescence photomicrographs show the distribution of S100 and N-CAM immunoreactivity within the intramuscular nerve trunks from serial sections of 25-month denervated and contralateral control TA muscles of 29-month-old rats. A, B Intramuscular nerve from a control muscle double stained for S100 (A) and laminin (B). Note that positive labeling is present in the cytoplasm of the Schwann cells surrounding both myelinated (arrowheads) and unmyelinated (arrows) axons: In myelinated nerve fibers the myelin sheath remains unstained (looks like a single black circle), whereas the inner and outer surfaces of the Schwann cells are positively labeled (double white circles). C, D Intramuscular nerve shown in $\mathbf{A} / \mathbf{B}$ double stained for N-CAM (C) and laminin (D). Note that N-CAM-labeled Schwann cells are present in a few bundles of unmyelinated axons (arrowheads), whereas the majority of the myelinated fibers are unstained. E-G Intramuscular nerve trunk from a 25 -month denervated muscle triple stained for S100 (E), laminin (F) and DAPI (G). Note that several S100labeled sites are clearly detected inside the endoneurial space (arrowheads). The small-size dots positive for $\mathrm{S} 100$ that are scattered throughout the endoneurial space are most likely the cross-sectioned processes of surviving Schwann cells. H-J Intramuscular nerve trunk shown in $\mathbf{E}-\mathbf{G}$ triple stained for N-CAM $(\mathbf{H})$, laminin (I) and DAPI (J). Note that the anti-N-CAM antibody labels several sites within the endoneurium in a pattern that resembles Schwann cell locations (arrows) (S100 S-100 protein, TA tibialis anterior, $N$-CAM neural cell adhesion molecule). Bars A-D $31 \mu \mathrm{m}$, E-J $24.8 \mu \mathrm{m}$ 

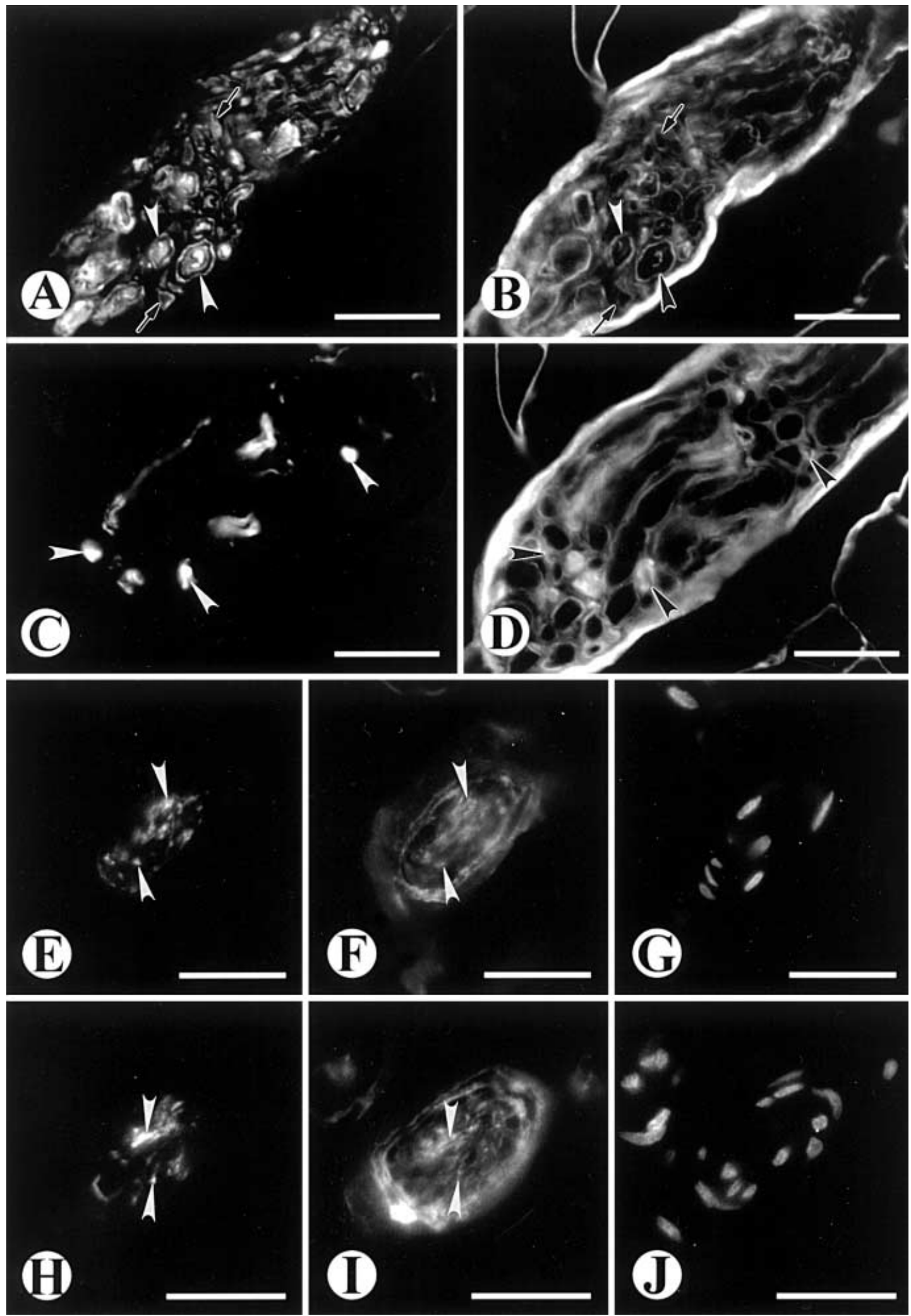

Practically all of the myelinated fibers as well as perineurial cells were N-CAM negative. In a 25-month denervated TA muscle, a small number of Schwann cells remaining inside the intramuscular nerve trunk continued to be both S100 (Fig. 2E-G) and N-CAM (Fig. 2H-J) posi- tive, whereas the perineurial cells displayed no labeling. Furthermore, a similar pattern of N-CAM-positive staining was also detected within the intramuscular nerve trunk of a 25-month denervated EDL muscle (Fig. 3). 

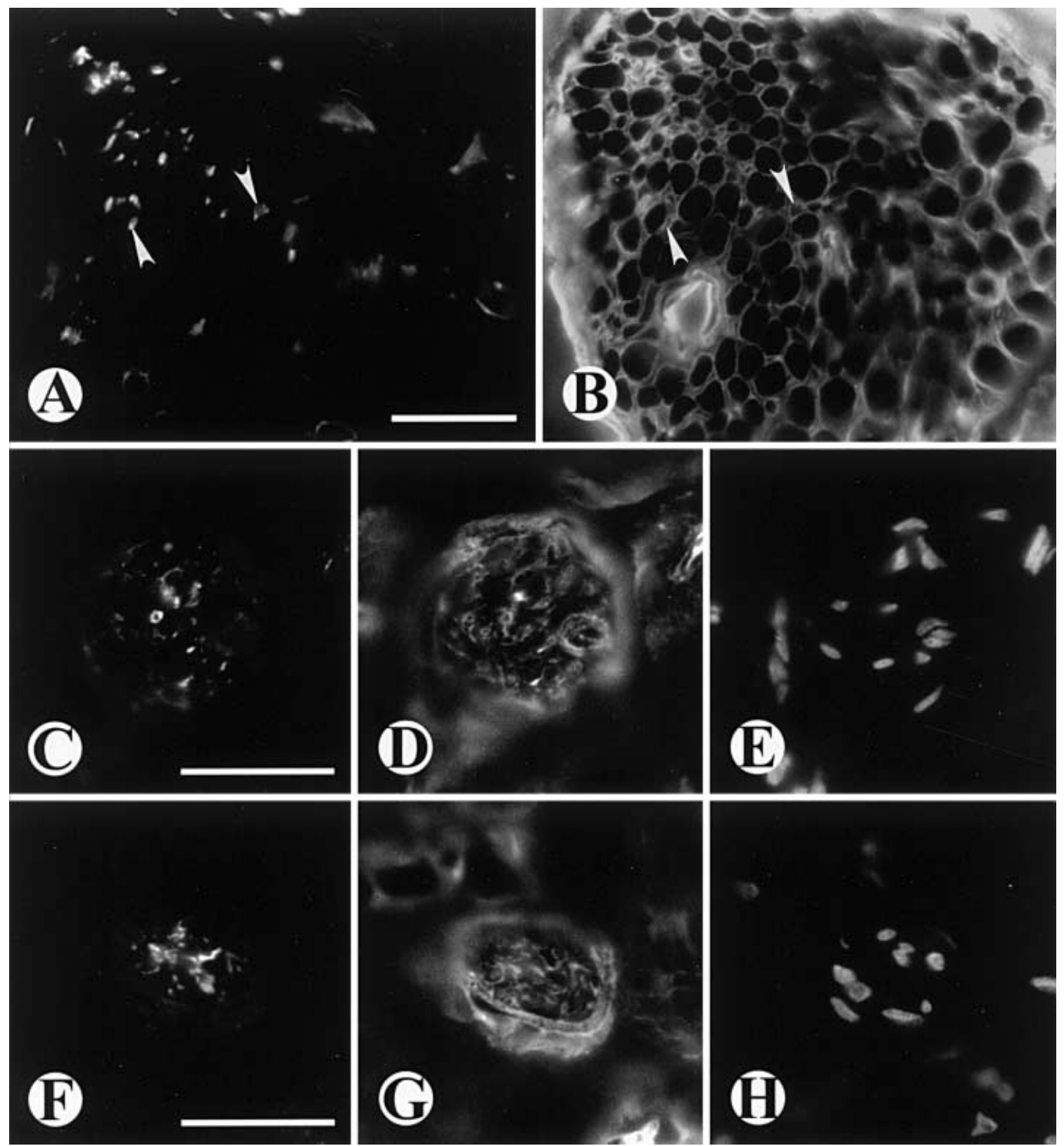

Fig. 3A-H Immunofluorescence photomicrographs show the distribution of N-CAM immunoreactivity within the intramuscular nerve trunks of 25-month denervated and contralateral control EDL muscles of 29-month-old rats. A, B Intramuscular nerve from a control muscle double stained for N-CAM (A) and laminin (B). Note that N-CAM-positive labeling is present exclusively in the cytoplasm of the Schwann cells surrounding unmyelinated axons (arrowheads). C-E Intramuscular nerve trunk from a 25-month denervated muscle triple stained for N-CAM (C), laminin (D) and DAPI (E). Note that several N-CAM-labeled dots are detected inside the endoneurial space. $\mathbf{F}-\mathbf{H}$ Intramuscular nerve trunk triple stained for N-CAM $(\mathbf{F})$, laminin $(\mathbf{G})$ and DAPI $(\mathbf{H})$. Note that the N-CAM-positive sites observed inside the endoneurial space are most likely the surviving Schwann cells. Bars A-H $32 \mu \mathrm{m}$

BDNF and trkB T, but not $\mathrm{p} 75$ are detected in 25-month denervated muscle

In RT-PCR and Western blot analyses, the distal stump of 2-month transected sciatic nerve and/or brain from 28 - month-old rats served as positive controls for the expression of BDNF, trkB T, trkB FL and p75 at the RNA and/or protein levels; normal sciatic nerve and control gastrocnemius muscle were used as additional controls for comparison with 25-month denervated muscle. RT-PCR analysis showed that BDNF and trkBT mRNA transcripts were present in a chronically denervated gastrocnemius muscle, whereas p75 mRNA was undetectable (Fig.4A, lane dGM). In addition, BDNF and trkB T mRNAs were found in the $\mathrm{SN}$ and in control gastrocnemius muscle as well as in the dSN (Fig. 4A). p75 mRNA, which was undetectable in the $\mathrm{SN}$ and in control muscle, became noticeable in the distal part of a 2-month transected SN (Fig.4A, lane $\mathrm{dSN}$ ). Interestingly, the trkB FL mRNA transcripts coding a catalytic form of the tyrosine protein kinase receptor $\mathrm{B}$ were only found in the brain (Fig. 4A, lane B). Concurrently, Western blot analysis showed that trkB $\mathrm{T}$ protein of 
A

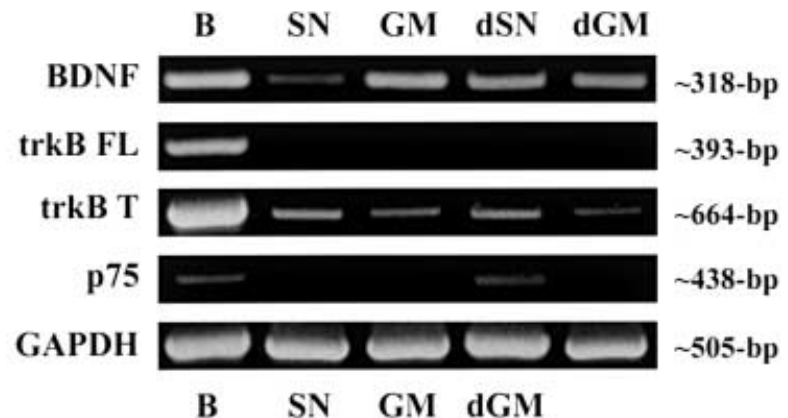

B

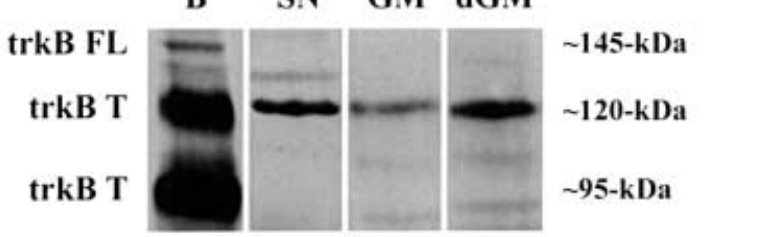

C

D

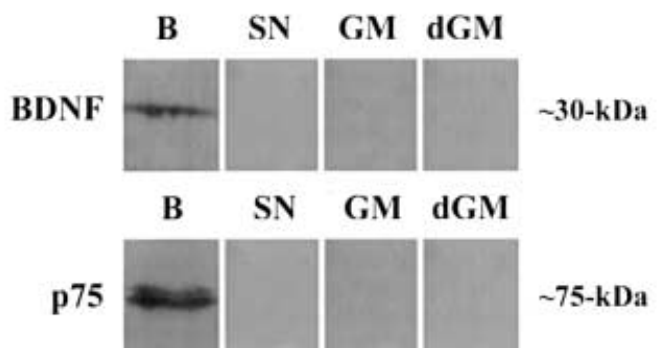

Fig. 4A-D RT-PCR and Western blot analyses of the expression of BDNF, trkB FL, trkB T, and p75 in the 25-month denervated GM. A RT-PCR analysis showing the mRNA expression of BDNF, trkB FL, trkB T, and p75. Note that the mRNA transcripts of both BDNF and trkB T are present in a 25 -month denervated muscle. GAPDH amplification was used as a control for quality and quantity of RNA in each sample. B Western blot analysis showing the expression of trkB. Note that the trkB T protein of $\sim 120 \mathrm{kDa}$ is present in all tissue extracts including 25 -month denervated muscle. C Western blot analysis showing expression of BDNF. Note that the BDNF precursor protein of $\sim 30 \mathrm{kDa}$ is present only in the brain. D Western blot analysis showing expression of p75. Note that the p75 band is present only in the brain ( $R T$ reverse transcription, $B D N F$ brain-derived neurotrophic factor, $B$ brain, $S N$ sciatic nerve, $G M$ gastrocnemius muscle, $d S N$ distal part of a 2-month transected SN, $d G M$ 25-month denervated GM)

about $120 \mathrm{kDa}$ was found in all examined extracts, including 25-month denervated muscle (Fig.4B, lane dGM). Only brain showed clear expression of trkB FL $(\sim 145 \mathrm{kDa})$ and two trkB $\mathrm{T}$ protein isoforms of $\sim 95$ and $\sim 120 \mathrm{kDa}$ (Fig. $4 \mathrm{~B}$, lane B). Although the mature form of BDNF protein $(\sim 14.5 \mathrm{kDa})$ was undetectable in any of the examined extracts, the $30-\mathrm{kDa}$ BDNF precursor protein was found in the brain (Fig.4C, lane B). Moreover, the low-affinity nerve growth factor receptor protein p75 was found at a detectable level only in the brain (Fig. 4D, lane B).

\section{Discussion}

In this study, we demonstrated that: (1) a small population of Schwann cells remains inside the intramuscular nerve trunks of 25-month denervated skeletal muscles; (2) the surviving Schwann cells continue to express S100 and
N-CAM; and (3) BDNF and its non-catalytic receptor trkB $\mathrm{T}$ are detected at RNA and/or protein levels in chronically denervated skeletal muscles.

Survival of Schwann cells in a chronically transected segment of peripheral nerve

The possibility of extended survival of Schwann cells within the intramuscular nerve trunks of chronically denervated skeletal muscles was the principal issue of our study. According to previous data, Schwann cells undergo progressive atrophy and degeneration in the chronically transected rat sciatic nerve, and are eventually replaced by connective tissue during 1 year following a nerve lesion $[31,44,45,47]$. Recently, in the contrast to these data, Bradley et al. [2] reported that despite the fact that Schwann cells in the distal stump of severed rabbit sciatic nerves become atrophic and partially disappear from the endoneurial space, some of the Schwann cells could survive up to 26 months after nerve injury. Taking into account these contradictory results, the first question that arose in our study was the possibility of identifying Schwann cells among the other cell types remaining in the deteriorated intramuscular nerve trunks of 25-month denervated skeletal muscles. It is known that recognition of the cell types of the peripheral nerve, such as the Schwann cells, endoneurial fibroblasts, and perineurial cells, becomes difficult under circumstances when their normal structural relationships are disturbed [13, 16, 45]. For example, Hirose et al. [13] and Sharma et al. [35] observed evidence of morphological and functional transitions between Schwann cells and perineurial cells, as well as between perineurial cells and endoneurial fibroblasts, in peripheral nerve sheath tumors. Despite the fact that endoneurial fibroblasts could acquire some characteristics of perineurial cells in the distal stump of a chronically transected peripheral nerve, the Schwann cells always preserve their distinct phenotype [2, 31, 41, 45]. Our study confirmed that the viable Schwann cells of the distal nerve stump continue to maintain their unique ultrastructural characteristics, such as the continuous basal lamina and closely packed cell processes, even 25 months after nerve transection.

It was previously reported that the Schwann cells of a peripheral nerve synthesize $\mathrm{S} 100$, whereas perineurial cells and endoneurial fibroblasts are S100 negative [36]. Several investigators have proposed that the immunopositive reactivity for the S100 is a useful tool to identify the Schwann cells remaining within an altered peripheral nerve after a traumatic lesion [21, 32, 47]. Their studies have demonstrated that $\mathrm{S} 100$ continues to be detectable in the Schwann cells remaining within a non-regenerated segment of sciatic nerve for half of a year following nerve transection. In our study, immunopositive reactivity for S100 was detected inside the intramuscular nerve trunks of skeletal muscles denervated for more than 2 years.

Taken together, our results demonstrate that surviving Schwann cells have the ability to maintain their popula- 
tion inside the intramuscular nerve trunks of chronically denervated skeletal muscles.

Do Schwann cells under condition of prolonged axonal withdrawal continue to express molecules that promote nerve repair?

A crucial question concerning Schwann cells remaining within the nerve trunks of chronically denervated skeletal muscles is their ability to preserve the production of molecules that are necessary to promote reparative axonal growth. Several lines of evidence confirm that Schwann cells remaining in the distal stamp of injured peripheral nerves begin to synthesize proteins associated with neuronal survival and axonal regeneration early after a nerve lesion $[6,15,22,40]$. It has also been shown that the distal stump of chronically transected peripheral nerve has the ability to attract axons for a long period of time following a nerve lesion [7, 37, 44]. However, recent experimental data suggest that the Schwann cells of distal stumps of permanently cut peripheral nerves eventually lose their ability to support axonal regeneration as a result of the cessation of specific gene activity $[11,47]$. To test this hypothesis in respect to the Schwann cells of the intramuscular nerve trunks, we studied the expression of $\mathrm{N}$-CAM, BDNF, trkB $\mathrm{T}$, and $\mathrm{p} 75$ in a 25 -month denervated skeletal muscle. We chose these molecules based on the fact that their expression has been shown to be the longest detectable in the distal stump of a transected sciatic nerve $[2,4,8,9,12,24,25,38,47]$.

In a normal peripheral nerve, N-CAM is expressed exclusively by unmyelinated fibers and non-myelinating Schwann cells $[4,23,30]$. A similar result was obtained in our study of the intramuscular nerves of control TA muscles, where only some unmyelinated fibers were N-CAM immunopositive. In an injured peripheral nerve, N-CAM has been implicated in the outgrowth and pathfinding of regenerating axons [22]. Experimental evidence has shown that the Schwann cells of an adult sciatic nerve rapidly up-regulate $\mathrm{N}$-CAM expression after the nerve damage and sharply down-regulate its synthesis following the full restoration of axon-Schwann cell contacts [4, 24]. Recently, Li et al. [21] reported that Schwann cells isolated from the distal stump of 6-month transected rat sciatic nerves and cultured in vitro continued to express $\mathrm{N}$ CAM. Our results showed N-CAM-positive labeling of Schwann cells inside the endoneurial space of intramuscular nerve trunks of 25-month denervated skeletal muscles. This supports the idea that the Schwann cells can maintain up-regulated expression of N-CAM for a very long time after nerve fiber withdrawal.

BDNF is a motor neuron survival factor synthesized in peripheral organs and transported through the axons towards the neuron bodies located in the central nervous system to prevent their degeneration and death $[18,34$, 46]. Under normal circumstances, a detectable level of BDNF mRNA is seen in the sciatic nerve and in hindlimb skeletal muscles of adult rats $[8,9,25]$. Our data, showing that the BDNF mRNA is detected in both normal sciatic nerve and control gastrocnemius muscle of 29-month-old rats, are also consistent with these results. It has been previously reported that an elevated level of BDNF mRNA is seen in the distal stump of the transected adult rat sciatic nerve [25] and in 1- and 2-week denervated adult rat gastrocnemius muscle $[8,9,18]$. Furthermore, using an in situ hybridization technique, Funakoshi et al. [8] and Griesbeck et al. [9] have shown that BDNF mRNA is restricted to the Schwann cells in the distal stump of a transected sciatic nerve trunk, including its branches within the denervated hindlimb skeletal muscles. In our study, prominent expression of BDNF mRNA was also detected in the distal segment of 2-month transected sciatic nerve and in 25-month denervated muscle. Nevertheless, neither mature nor precursor forms of BDNF protein were detected by Western blot analyses in any muscle and sciatic nerve sample examined in our study. Although the issue concerning the cell type origin of BDNF production in denervated skeletal muscle has not been obviously addressed in our study we have showed that BDNF mRNA was synthesized in severely atrophic skeletal muscle more then 2 years after axon withdrawal.

It has been shown that BDNF initiates its biological effects on cells by binding to the high-affinity receptor trkB that belongs to a tyrosine protein kinase receptor family $[1,3]$. In the brain, trkB exists both as a full-length protein (trkB FL) and its truncated forms (trkB T), which lacks a catalytic intracellular tyrosine kinase domain $[17,26]$. mRNA coding only a non-catalytic trkB $\mathrm{T}$ receptor has been detected in sciatic nerve and skeletal muscle $[8,33]$. Consistent with these results, in our study, expression of trkB $\mathrm{T}$ was detected in all muscle and sciatic nerve samples, whereas only brain showed the presence of trkB FL at both mRNA and protein levels. It has also been reported that trkB T mRNA displayed either unaltered or reduced level of expressions in the distal stump of a transected sciatic nerve $[5,8,33]$, and in a denervated skeletal muscle [8]. In our study, mRNA and protein expressions of trkB $\mathrm{T}$ also seemed to be only slightly reduced in 25-month denervated muscle compared to control muscle. Recently, Nakajima et al. [28] proposed that the trkB T protein of about $95 \mathrm{kDa}$ in tissue extract could be present as differently glycosylated forms with molecular masses of around 120 or $130 \mathrm{kDa}$. Taking this fact into account, we suggest that the $\sim 120-\mathrm{kDa}$ band detected in all samples examined by Western blotting may be a glycosylated form of the trkB T protein. Frisen et al. [5] and Funakoshi et al. [8] have showed that the expression of trkB $\mathrm{T}$ mRNA in sciatic nerve is restricted to the Schwann cells. Furthermore, trkB immunoreactivity was detected only on the surface of Schwann cells [5]. Based on these observations, we suggest that the Schwann cells remaining in the intramuscular nerve trunks might be the source of the mRNA and protein expression of the trkB $\mathrm{T}$ in the 25-month denervated skeletal muscle.

It has previously been reported that the level of p75 mRNA expression is increased in the transected sciatic nerve $[12,47]$. Moreover, the expression of p75 protein is 
elevated in denervated hindlimb skeletal muscles, while immunoreactivity with p75 protein is detected on the Schwann cells within intramuscular nerve fascicles of denervated muscle [38, 39]. Nevertheless, according to the data obtained by You et al. [47] and Bradley et al. [2], expression of p75 becomes barely detectable on Schwann cells surviving up to 6 months in the distal stump of a chronically transected sciatic nerve. Consistent with these data, in our study, expression of p75 mRNA was found in the distal stump of 2-month transected sciatic nerve, but was completely undetectable in the 25 -month denervated muscle.

In conclusion, our results support the idea that a small population of viable Schwann cells, which maintain the ability to express some of the cell-specific proteins, can survive within the intramuscular nerve trunks of 25-month denervated skeletal muscles.

Acknowledgements We thank Dr. Daniel Goldman for permitting us to use equipment in his laboratory. Original research was supported by NIH grant PO1-AG10821. T. Y. K. was supported by NIA research training grant T32-AG00116.

\section{References}

1. Barbacid M (1994) The trk family of neurotrophin receptors. J Neurobiol 25:1386-1403

2. Bradley JL, Abernethy DA, King RH, Muddle JR, Thomas PK (1998) Neural architecture in transected rabbit sciatic nerve after prolonged nonreinnervation. J Anat 192:529-538

3. Chao MV (1992) Neurotrophin receptors: a window into neuronal differentiation. Neuron 9:583-593

4. Daniloff JK, Levi G, Grumet M, Rieger F, Edelman GM (1986) Altered expression of neuronal cell adhesion molecules induced by nerve injury and repair. J Cell Biol 103:929-945

5. Frisen J, Verge VMK, Fried K, Risling M, Persson H, Trotter J, Hokfelt T, Lindholm D (1993) Characterization of glial trkB receptors: differential response to injury in the central and peripheral nervous systems. Proc Natl Acad Sci USA 90:49714975

6. Frostick SP, Yin Q, Kemp GJ (1998) Schwann cells, neurotrophic factors, and peripheral nerve regeneration. Microsurgery 18:397-405

7. Fu SY, Gordon T (1995) Contributing factors to poor functional recovery after delayed nerve repair: prolonged denervation. J Neurosci 15:3886-3895

8. Funakoshi H, Friesen G, Barbany G, Timmusk T, Zachirisson O, Verge VMK, Persson H (1993) Differential expression of mRNAs for neurotrophins and their receptor after axotomy of the sciatic nerve. J Cell Biol 123:455-465

9. Griesbeck O, Parsadanian AS, Sendtner M, Thoenen H (1995) Expression of neurotrophins in skeletal muscle: quantitative comparison and significance for motoneuron survival and maintenance of function. J Neurosci Res 42:21-33

10. Hall SM (1986) Regeneration in cellular and acellular autografts in the peripheral nervous system. Neuropathol Appl Neurobiol 12:27-46

11. Hall SM (1999) The biology of chronically denervated schwann cells. Ann NY Acad Sci 883:215-233

12. Heumann R, Lindholm D, Bandtlow C, Meyer M, Radeke MJ, Misko TP, Shooter E, Thoenen H (1987) Differential regulation of mRNA encoding nerve growth factor and its receptor in rat sciatic nerve during development, degeneration, and regeneration: role of macrophages. Proc Natl Acad Sci USA 84: 8735-8739
13. Hirose T, Sano T, Hizawa K (1986) Ultrastructural localization of S-100 protein in neurofibroma. Acta Neuropathol (Berl) 69: $103-110$

14. Holmes W, Young JZ (1942) Nerve regeneration after immediate and delayed suture. J Anat 77:63-106

15. Ide C (1996) Peripheral nerve regeneration. Neurosci Res 25: $101-121$

16. Jurecka W, Ammerer HP, Lassmann H (1975) Regeneration of a transected peripheral nerve. Acta Neuropathol (Berl) 32: 299-312

17. Klein R, Conway D, Parada LF, Barbacid M (1990) The trkB tyrosine protein kinase gene codes for a second neurogenic receptor that lacks the catalytic kinase domain. Cell 61:647-656

18. Koliatsos VE, Clatterbuck RE, Winslow JW, Cayouette MH, Price DL (1993) Evidence that brain-derived neurotrophic factor is a trophic factor for motor neurons in vivo. Neuron 10:359-367

19. Lee S-L, Kim J-K, Kim D-S, Cho H-J (1999) Expression of mRNAs encoding full-length and truncated TrkB receptors in rat dorsal root ganglia and spinal cord following peripheral inflammation. NeuroReport 10:2847-2851

20. Li H, Terenghi G, Hall SM (1997) Effects of delayed reinnervation on the expression of c-erbB receptors by chronically denervated rat Schwann cells in vivo. Glia 20:333-347

21. Li H, Wigley C, Hall SM (1998) Chronically denervated rat Schwann cells respond to GGF in vitro. Glia 24:290-303

22. Martini R (1994) Expression and functional roles of neural cell surface molecules and extracellular matrix components during development and regeneration of peripheral nerves. J Neurocytol 23:1-28

23. Martini R, Schachner M (1986) Immunoelectron microscopic localization of neural cell adhesion molecules (L1, N-CAM, and MAG) and their shared carbohydrate epitope and myelin basic protein in developing sciatic nerve. J Cell Biol 103: 2439-2448

24. Martini R, Schachner M (1988) Immunoelectron microscopic localization of neural cell adhesion molecules (L1, N-CAM, and myelin-associated glycoprotein) in regenerating adult mouse sciatic nerve. J Cell Biol 106:1735-1746

25. Meyer M, Matsuoka I, Wetmore C, Thoenen H (1992) Enhanced synthesis of brain-derived neurotrophic factor in the lesioned peripheral nerve: different mechanisms are responsible for the regulation of BDNF and NGF mRNA. J Cell Biol 119: $45-54$

26. Middlemas DS, Lindberg RA, Hunter T (1991) trkB, a neural receptor protein-tyrosine kinase: evidence for a full-length and two truncated receptors. Mol Cell Biol 11:143-153

27. Nadim W, Anderson PN, Turmaine M (1990) The role of Schwann cells and basal lamina tubes in the regeneration of axons through long lengths of freeze-killed nerve grafts. Neuropathol Appl Neurobiol 16:411-421

28. Nakajima K, Kikuchi Y, Ikoma E, Honda S, Ishikawa M, Liu Y, Kohsaka S (1998) Neurotrophins regulate the function of cultured microglia. Glia 24:272-289

29. Pellegrino RG, Spencer PS (1985) Schwann cell mitosis in response to regenerating peripheral axons in vivo. Brain Res 341:16-25

30. Roche P-H, Figarella-Branger D, Daniel L, Bianco N, Pellet W, Pellissier J-F (1997) Expression of cell adhesion molecules in normal nerves, chronic axonal neuropathies and Schwann cell tumors. J Neurol Sci 151:127-133

31. Roytta M, Salonen V (1988) Long-term endoneurial changes after nerve transection. Acta Neuropathol 76:35-45

32. Salonen V, Aho H, Roytta M, Peltonen J (1988) Quantitation of Schwann cells and endoneurial fibroblast-like cells after experimental nerve trauma. Acta Neuropathol (Berl) 75:331-336

33. Sebert ME, Shooter EM (1993) Expression of mRNA for neurotrophic factors and their receptors in the rat dorsal root ganglion and sciatic nerve following nerve injury. J Neurosci Res 36:357-367 
34. Sendtner M, Holtmann B, Kolbeck R, Thoenen H, Barde Y-A (1992) Brain-derived neurotrophic factor prevents the death of motoneurons in newborn rats after nerve section. Nature 360:757-759

35. Sharma S, Sarkar C, Mathur M, Dinda AK, Roy S (1990) Benign nerve sheath tumors: a light microscopic, electron microscopic and immunohistochemical study of 102 cases. Pathology 22:191-195

36. Stefansson K, Wollmann RL, Moore BW (1982) Distribution of S-100 protein outside the central nervous system. Brain Res 234:309-317

37. Sulaiman OAR, Gordon T (2000) Effects of short- and longterm Schwann cell denervation on peripheral nerve regeneration, myelination, and size. Glia 32:234-246

38. Taniuchi M, Clark B, Johnson EM (1986) Induction of nerve growth factor receptor in Schwann cells after axotomy. Proc Natl Acad Sci USA 83:4094-4098

39. Taniuchi M, Clark HB, Schweitzer JB, Johnson EM (1988) Expression of nerve growth factor receptors by Schwann cells of axotomized peripheral nerves: ultrastructural location, suppression by axonal contact, and binding properties. J Neurosci 8: 664-681

40. Terenghi G (1999) Peripheral nerve regeneration and neurotrophic factors. J Anat 194:1-14

41. Terenghi G, Calder JS, Birch R, Hall SM (1998) A morphological study of schwann cells and axonal regeneration in chronically transected human peripheral nerves. J Hand Surg $[\mathrm{Br}]$ 23B:583-587
42. Torigoe K, Tanaka HF, Takahashi A, Awaya A, Hashimoto K (1996) Basic behavior of migratory Schwann cells in peripheral nerve regeneration. Exp Neurol 137:301-308

43. Viguie C A, Lu D-X, Huang S-K, Rengen H, Carlson BM (1997) Quantitative study of the effects of long-term denervation on the extensor digitorum longus muscle of the rat. Anat Rec 248:346-354

44. Vuorinen V, Siironen J, Roytta M (1995) Axonal regeneration into chronically denervated distal stump. 1. Electron microscope studies. Acta Neuropathol 89:209-218

45. Weinberg HJ, Spencer PS (1978) The fate of Schwann cells isolated from axonal contact. J Neurocytol 7:555-569

46. Yan Q, Elliott J, Snider WD (1992) Brain-derived neurotrophic factor rescues spinal motor neurons from axotomy-induced cell death. Nature 360:753-755

47. You S, Petrov T, Chung PH, Gordon T (1997) The expression of the low affinity nerve growth factor receptor in long-term denervated Schwann cells. Glia 20:87-100

48. Zaheer A, Zhong W, Uc EY, Moser DR, Lim R (1995) Expression of mRNAs of multiple growth factors and receptors by astrocytes and glioma cells: detection with reverse transcriptionpolymerase chain reaction. Cell Mol Neurobiol 15:221-237 